\title{
As interações entre os produtos estéticos para cabelos crespos e as mulheres negras
}

\author{
Aline Tusset De Rocco \\ Universidade do Vale do Rio dos Sinos, Brasil \\ (D) https://orcid.org/0000-0003-3647-9204 \\ atussetderocco@gmail.com
}

\section{Introdução}

A população negra na diáspora tem tido seus direitos e cidadania negados há muito tempo, isso inclui também a inclusão social e econômica, ou seja, também compreende o consumo. Autores como Sansone (2000) e Canclini (1996) defendem a relação entre consumo e direitos sociais, assim como apresentam o consumo como uma voz da população que busca não só por status, mas também por cidadania. Consumir vai além do senso comum que liga o ato a uma ideia de esgotamento, é também transformar uma mercadoria em algo seu, dandolhe um novo significado e podendo utilizar-se dele para comunicar-se com o mundo.

Assim, neste artigo será abordado o conceito de consumo a partir da visão antropológica de Douglas e Isherwood (2006), assim como as 
relações e ressignificações do consumo cotidiano trazido por Certeau (1994). Ainda, aborda-se a visão antropológica do consumo buscando um maior entendimento dos processos de consumo da população negra. Ao final, trazem-se visões e dados que articulam o consumo com as especificidades da população negra, e principalmente ao consumo estético e as mulheres negras.

\section{Uma visão antropológica a cerca do consumo da mulher negra}

O consumo é uma categoria central na definição e estudo da sociedade contemporânea. Ao mesmo tempo em que é um processo social que diz respeito à provisão de bens, é também um mecanismo social percebido como um produtor de sentidos e identidades. São diversas as questões que se deve levar em consideração ao falar de consumo como experiência cultural de nosso tempo: pode-se pensar sobre a significação dos produtos, seu simbolismo, a relação com práticas sociais, seu sentido classificatório, seu poder de exclusão, entre tantas outras. Em síntese, mostra-se pertinente conhecer a lógica e o significado cultural dos objetos para entender o consumo como eixo marcante da singularidade de nosso tempo. O olhar proposto neste artigo se interessa pelos impactos socioculturais do consumo e sobre como este pode revelar identidades estéticas e políticas.

As práticas de consumo interferem no modo como vemos os outros e nos reconhecemos a nós mesmos. Apesar disso, é preciso que não sejamos ingênuos a ponto de acreditar que o consumo pode sanar todas as bases sociais da exclusão. Ademais, faz-se necessário lembrar que o consumo e a produção são parte de um mesmo processo circular, então, é indispensável que olhemos para além dos processos 
de trabalho, mas também para os usos e significados dos bens materiais (DOUGLAS; ISHERWOOD, 2006).

Para começar, é preciso compreender os bens como necessários para dar visibilidade e estabilidade às categorias culturais, sendo importantes comunicadores para uma análise cultural. Os bens que servem às necessidades físicas, como comida e bebida, não são menos portadores de significados do que uma dança. Portanto, o significado está nas relações entre os bens.

Para tratarmos dos usos singulares concedidos às mercadorias, buscamos, através do pensamento de Michel de Certeau, apresentar algumas concepções acerca do consumo, de modo a agregar ao pensamento do consumo em seu viés antropológico. Para Certeau (1994), a presença e circulação de uma mercadoria não representam o que esta significa para seu usuário; para o autor, a relação de manipulação dos produtos é essencial para o entendimento do consumo. Ainda, a sociedade seria composta de instituições organizadoras e nela as práticas do consumo devem ser relacionadas à ideia de poder majoritário e minoritário. Desse modo, o sistema, “em vez de esmagar os grupos para marcá-los com o ferro único de um só poder, atomiza-os inicialmente e depois multiplica as redes estreitas dos intercâmbios que conformam unidades individuais e culturais” (CERTEAU, 1994, p. 241). Em contraponto, para Certeau (1994), as práticas de consumo possibilitam uma espécie de agência em que se propõem a romper com a ideia de massificação, possibilitando práticas das quais o indivíduo possui o poder de ressignificação.

Assim, Michel de Certeau (1994) nos possibilita compreender o consumo enquanto espaço de produção de sentidos, apresentando os indivíduos como apropriadores de produtos culturais através de uma espécie de estratégia. Certeau (1994), ao tratar das “maneiras de fa- 
zer”, acredita que, através da ressignificação do consumo dada pelo indivíduo, inverte-se a relação de dominação. Para o autor, estas “ 'maneiras do fazer' constituem as mil práticas pelas quais usuários se reapropriam do espaço organizado pelas técnicas da produção sóciocultural” (CERTEAU, 1994, p. 41). As “maneiras de fazer” são, então, as microrresistências que proporcionam agência aos indivíduos através da ressignificação do consumo.

Logo, faz-se necessário diferenciar as "ações” e distinguir os manuseios feitos pelos usuários e pelo sistema do produto. Dessa maneira, Certeau (1994) defende que as táticas do consumo se desenvolvem em meio a tensões e são modos de politizar a prática cotidiana através das “engenhosidades” dos supostamente mais fracos, ou seja, dos usuários. Assim, táticas seriam desvios da racionalidade imposta capazes de gerar efeitos imprevisíveis. É através desta linha de raciocínio que Certeau defende que o consumo vai além da produção e distribuição das mercadorias, e se faz essencial sua compreensão de uso e de manipulação simbólica dada pelos indivíduos.

Depois dos trabalhos, muitos deles notáveis, que analisaram os "bens culturais", o sistema de sua produção, o mapa de sua distribuição e a distribuição dos consumidores nesse mapa, parece possível considerar esses bens não apenas como dados a partir dos quais se pode estabelecer os quadros estatísticos de sua circulação ou constatar os funcionamentos econômicos de sua difusão, mas também como o repertório com o qual os usuários procedem a operações próprias. Sendo assim, esses fatos não são mais os dados de nossos cálculos, mas o léxico de suas práticas. Assim, uma vez analisadas as imagens distribuídas pela TV e os tempos que se passa assistindo aos programas televisivos, resta ainda perguntar o que é que o consumidor fabrica com essas imagens e durante essas horas. Os 500 mil franceses que compram Information-santé, os fregueses do supermercado, os praticantes do espaço urbano, os consumidores das histórias e legendas jornalísticas, o que é que eles “absorvem”, rece- 
bem e pagam? O que fazem com isso? (CERTEAU, 1994, p. 93).

Certeau (1994) defende assim que quem consome um produto ou serviço não é apenas um indivíduo passivo e massificado, mas é capaz de transformar e assimilar o que consome dando seu próprio significado. Aqui, o consumidor não pode ser qualificado apenas conforme o que consome, distanciando-se o que lhe é oferecido e o uso que faz do produto ou serviço. De acordo com Certeau (1994), deve-se analisar o uso por si próprio, assim, “a produção fornece o capital e os usuários, como locatários, adquirem o direito de efetuar operações sobre este fundo sem serem os seus proprietários” (CERTEAU, 1994, p. 96).

Se as “maneiras de fazer” de Certeau (1994) são as práticas de reapropriação dos usuários, a chamada "cultura popular" a que o autor se refere se formula nas "artes de fazer”, ou seja, através de consumos combinatórios e utilitários. As “artes de fazer” nada mais são do que os usos dados pelos indivíduos através de produtos culturais, transformando-os, através de práticas, em novas artes de fazer. Desse modo, a arte de fazer é forjada em práticas de resistência do cotidiano, é uma espécie de antidisciplina, uma astúcia dos indivíduos para ressignificar um produto.

Em seguida, Certeau (1994) trata dos conceitos de estratégias e táticas, os quais são de extrema relevância para a compreensão da linha de pensamento do autor sobre o consumo.

As estratégias são, portanto, ações que, graças ao postulado de um lugar de poder (à propriedade de um próprio), elaboram lugares teóricos (sistemas e discursos totalizantes), capazes de articular um conjunto de lugares físicos onde as forças se distribuem. Elas combinam esses três tipos de lugar e visam dominá-los uns pelos outros. Privilegiam, portanto, as relações espaciais. Ao menos procuram elas reduzir a esse tipo as relações temporais pela atribuição analítica 
de um lugar próprio a cada elemento particular e pela organização combinatória dos movimentos específicos a unidades ou a conjuntos unidades. O modelo para isso foi antes o militar que o "científico". As táticas são procedimentos que valem pela pertinência que dão ao tempo - às circunstâncias que o instante preciso de uma intervenção transforma em situação favorável, a relações entre momento que mudam a organização do espaço, às relações entre momentos sucessivos de um "golpe", aos cruzamentos possíveis de durações e ritmos heterogêneos etc. Sob este aspecto, a diferença entre umas e outras remete a duas opções históricas em matéria de ação e segurança (opções que respondem aliás mais a coerções que a possibilidades): as estratégias apontam para a resistência que o estabelecimento de um lugar oferece ao gasto do tempo; as táticas apontam para uma hábil utilização do tempo, das ocasiões que apresenta e também dos jogos que introduz nas fundações de um poder. (CERTEAU, 1994, p. 102).

Percebe-se assim que as estratégias fazem referência às condições com as quais o indivíduo se depara, enquanto as táticas se relacionam às escolhas dos indivíduos frente ao consumo. As estratégias, então, correspondem a um cálculo de relação de forças que são base para a gestão das relações com uma exterioridade visando produzir, mapear e impor. Já as táticas, por sua vez, são ações de desvio, são as capacidades inventivas do indivíduo, e originam diferentes maneiras de fazer. Diferente das estratégias que mapeiam e produzem, as táticas são resultado da criatividade do indivíduo ao escapar do controle das empresas produtoras dos bens de consumo. Logo, muitas vezes as táticas e estratégias estabelecem uma tensão que é atualizada pelas experiências coletivas, mas também pelas individuais.

Assim, a capacidade de comunicação dos bens de consumo está relacionada à sua compreensão da cultura e de seus significados. É dessa maneira que a comunicação através do consumo se dá pelas práticas e rituais de como cada mercadoria é produzida e utilizada no cotidiano. Evidencia-se, assim, como o consumo se relaciona e pro- 
duz indivíduos diferenciados ao propor que estes possam redefinir e ressignificar uma mercadoria. As práticas de consumo se estabelecem entre as estratégias e as táticas, revelando-se parte da tensão percebida por Certeau (1994) e possibilitando a agência dos indivíduos através da sua ressignificação.

Buscando uma ressignificação através do consumo, a população negra, que até então tinha grande dificuldade de encontrar produtos de consumo estéticos para seus cabelos, começa a vislumbrar uma visibilidade.

No Brasil, até por volta dos anos 1990, os penteados afro ainda eram considerados arte corporal e não eram encontrados em salões de beleza, mesmo na Bahia. Coutinho (2009) atenta ao falar da dificuldade de encontrar profissionais especializados em cabelos afro: "Era mais fácil encontrar mulheres especializadas em passar ferro, 'fritar' os cabelos. O uso do cabelo afro estava muito relacionado com momentos festivos, especificamente com o carnaval” (COUTINHO, 2009, p. 5). Assim, é apenas no final do século XX que a população negra começa a despertar o interesse da indústria de cosméticos, e somente nos anos 1990 começa-se a vislumbrar a população negra sendo representada também na publicidade.

Logo, no Brasil, empresas de cosméticos e diversas revistas femininas traziam conselhos sobre como manter os cabelos saudáveis, entretanto, estas dicas sempre eram construídas dentro de um discurso "neutro”, silenciando o fato de visarem cabelos lisos e finos (XAVIER, 2011). Com o silenciamento da indústria cosmética em relação às mulheres negras, iniciou-se um movimento paralelo de empresas de afroempreendedores com propostas de produtos exclusivos para cabelos crespos. Os cabelos foram tema preponderante nas revistas com foco na população negra e assim, os produtos cosméticos se mostra- 
ram como fundamentais para a construção de um lugar de beleza para as mulheres negras.

Como decorrência do movimento negro, vêm ocorrendo políticas de ações afirmativas que buscam impulsionar o Brasil na direção de um Estado menos desigual socialmente. No final do século XX e começo do século XXI, no país, podemos perceber diversas expressões de valorização e orgulho negro, como produções acadêmicas e grupos de pesquisa visando à população negra, assim como as novas políticas públicas de inclusão racial. Além disso, a influência norte-americana, ao se disseminar pelo país, desenvolveu um novo movimento musical que valoriza a negritude para além da militância política: o funk. Além do funk, vemos diversos ritmos musicais que celebram a negritude, como o samba, o reggae, o blues e o rap. É importante ressaltar a contribuição dos movimentos políticos e musicais para a construção de novas formas de expressão e para o combate da inferiorização da imagem vinculada à negritude.

Assim, para autoras como Figueiredo (1994), desde os anos 1980 o corpo negro tem se ressignificado, tendo ganhado mais notoriedade no Brasil a partir do surgimento da Revista Raça Brasil na década de 1990. Conforme atenta Figueiredo (1994), as mulheres negras, fora do campo das conscientemente racializadas, possuem uma interação com o cabelo estimulada principalmente pelas condições econômicas. Para a autora, a manipulação envolve também o aspecto econômico, além da posição social da mulher negra. Vale ressaltar a diferenciação ao fazermos um recorte de classe, já que, conforme Cruz (2013), a classe $C$ não busca particularidade na sua identificação, e sim, uma igualdade de consumo. Ainda segundo Cruz (2013), tratar a luta antirracismo sem falar do embelezamento e dos cuidados com o corpo é reproduzir um pensamento masculino que não dá conta de compre- 
ender a condição das mulheres negras e sua relação com os cabelos crespos.

Opondo-se ao padrão estético europeu imposto no Brasil, a estética negra tem ganhado espaço em sua reivindicação por uma beleza negra.

Desse modo, inicia-se um processo de geração de mercadorias específicas que atendam à demanda de um público que não estava contemplado pelo mercado de cosméticos, o qual, até então, preocupavase em vender produtos para cabelos de modo generalista (ou seja, pensando apenas no cabelo padrão, o cabelo liso).

No Brasil, aos poucos a mulher negra começa a ganhar espaço e ser inserida dentro da demanda do consumo. No século XXI, vem se expandindo a representatividade da imagem da população negra nas mídias, seja em decorrência da ascensão social, do reposicionamento social e cultural da população negra, seja através das reivindicações dos movimentos negros. Além disso, tem aumentado o desenvolvimento de produtos classificados pela indústria como étnicos, que se destinam especificamente a afrodescendentes. Essa tendência de consumo étnico tem propiciado a visão da população negra como consumidora, além de valorizar sua identidade e cultura.

Ao tratar-se especificamente dos fatores que influenciam a decisão de consumo das mulheres negras, trazemos as ideias de Sheth et al. (2001) que abordam o comportamento dos indivíduos no consumo dentro do pensamento do Marketing. Para os autores, o ambiente e a cultura influenciam as preferências e gostos dos indivíduos, definindo o que estes buscam no consumo. O contexto pessoal que pode vir a influenciar as decisões do indivíduo é tratado em quatro dimensões pelos autores, seriam elas: a cultura, as instituições e grupos, o valor pessoal e a classe social. Assim, "a cultura e os grupos de referência 
influenciam os gostos e as preferências dos clientes, e o valor pessoal influencia seus recursos” (SHETH et al., 2011, p. 151), a classe social, como sabemos, influencia o poder de consumo.

Para Sheth et al. (2001), ${ }^{1}$ a família é o grupo de referência que exerce maior influência sobre qualquer consumidor individual. Assim, faz-se necessário, durante a etnografia, prestarmos maior atenção aos laços familiares e à possível influência dos outros indivíduos da família nas escolhas e posicionamentos das mulheres negras que serão base desta análise.

Outro fator que segundo os autores pode vir a influenciar padrões de consumo é a raça, já que itens de cuidado pessoal devem ter um desempenho específico no caso abordado neste estudo. Assim, o papel de consumidor pode ser afetado pela raça de dois modos distintos: primeiro, muitas vezes há uma preferência por vendedores, representantes, ou pessoas na mídia que sejam da mesma raça; segundo, cada grupo étnico pode vir a diferir no tipo de interação que estabelece com atendentes de lojas e suas mercadorias.

Ainda, quando se fala de consumo, pode-se atentar para a influência da personalidade na decisão do usuário. A personalidade pode estar relacionada a gostos pessoais, à lealdade a determinadas marcas e produtos, a escolhas e a estilos de vida. Tudo isso também se relaci-

\footnotetext{
${ }^{1}$ Sheth et al. (2001) vai ao encontro do pensamento do sociólogo alemão Axel Honneth (2003), que percebe a luta por reconhecimento como parte da construção identitária e da busca pela autonomia do indivíduo. Para Honneth (2003), as lutas sociais são lutas por reconhecimento, relacionadas tanto ao autorreconhecimento quanto ao reconhecimento do outro, e sendo capazes de gerar transformações sociais. Honneth afirma três esferas desta luta: o amor (relações afetivas); o direito (direito ao pertencimento); e a solidariedade (estima social). Assim como em Sheth et al. (2001), Honneth também percebe relações entre os indivíduos, a autoestima e a estima social; compreendendo a influência de subjetividades na construção identitária, assim como a necessidade dos indivíduos de se reconhecerem tanto como autônomos e livres, quanto como membros da sociedade.
} 
ona com a autoimagem que o indivíduo tem de si, buscando, através do consumo, reforçar ou até mesmo construir a sua identidade.

Quanto às motivações de consumo, vale ressaltar que muitos dos produtos que geram valor social também podem vir a gerar valor emocional. Por exemplo, comunicações que representam a população negra de forma positiva tendem a impactar socialmente e também a agregar valor emocional ao ato de consumo da mulher negra. Sheth et al. afirmam: “o marketing de causa social - programas que promovem causas como a unidade racial - desperta fortes elos emocionais da identificação em vários espectadores” (SHETH et al., 2001, p. 723).

Para Gonçalves e Ribeiro (2006), o consumo é um importante fator na construção de identidades da população negra, assim como para a sua inclusão. A abolição da escravatura, assim como a industrialização brasileira, influenciaram a criação de uma estética do negro na diáspora. Do mesmo modo, a exigência de boa aparência seja social, seja por motivos empregatícios, também levou a população negra ao consumo dos produtos estéticos, sejam eles caseiros ou industrializados. Deste modo, surgem as mercadorias chamadas de “étnicas” no mercado, concedendo à população negra a possibilidade de escolha e adesão a diferentes estilos estéticos (GONÇALVES; RIBEIRO, 2006, p. 62). Ao chegarem ao público, essas mercadorias, em sua maioria estrangeiras, foram adquiridas pela população negra de classe média ou alta. Entretanto, com a abertura do mercado brasileiro visando à estética negra, os preços dos produtos estéticos acabam por se tornarem mais baixos e, assim, de maior acesso à população negra em geral.

De acordo com Canclini (1996), as identidades contemporâneas estão diretamente ligadas ao consumo. Para o autor, a cidadania vai além dos aparelhos estatais, mas se faz principalmente através de práticas sociais e culturais, como, por exemplo, o consumo. Ainda, o 
autor atenta sobre o consumo: “é preciso analisar como esta área de apropriação de bens e signos intervém em formas mais ativas de participação do que aquelas que habitualmente recebem o rótulo de consumo” (CANCLINI, 1996, p. 31). Assim, o consumo seria uma ação pela qual os indivíduos não se posicionam apenas como trocadores de mercadorias, mas como parte das suas próprias interações sociais, sendo modo de distinção, satisfação biológica e simbólica.

Canclini (1996) sugere que, na América Latina, nem todos têm os mesmos direitos, e é assim que o consumo se torna também um instrumento de cidadania. De acordo com o autor, o direito de consumir se confunde com o direito de existir a partir do momento em que as reivindicações de direitos são atreladas a uma cidadania através do consumo. Segundo o pensamento de Canclini (1996), os gostos também podem ser vistos como parte da formação cultural de uma cidadania mais democrática. As opções de consumo inserem e dão novas possibilidades de construções simbólicas aos indivíduos. Apesar de concordar, em parte, com a desconexão das condições comuns que pode ser causada pelo consumo, Canclini (1996) também acredita que o consumo e os novos meios de comunicação possam gerar associações e lutas sociais.

Nas últimas décadas, devido à ascensão social de classes menos abastadas na sociedade brasileira e o maior acesso à educação por populações mais pobres e muitas vezes negras, o mercado também percebeu o poder de compra desses indivíduos. Através de lutas pelo reconhecimento de mulheres negras, sua posição de não submissão aos padrões impostos pela sociedade e o posicionamento político de assumir seu cabelo no aspecto natural, as novas mercadorias estéticas para mulheres negras ganharam espaço nas lojas e também na mídia. Posto isto, percebe-se uma abertura para a possível inclusão estética 
dessas mulheres através do consumo.

Entretanto, ao considerar a crescente integração da mulher negra ao consumo, pode-se observar algumas contradições. Se, por um lado, o consumo é instrumento de conquista de direitos civis e contribui para uma sensação de inclusão e cidadania, por outro, a população negra na diáspora tem sido constantemente relacionada ao consumo ostentoso, gerando um sentimento de exclusão racial àqueles que são privados do consumo de determinadas mercadorias (SANSONE, 2000).

É relevante pensar sobre o papel do consumo como marcador social para estas mulheres e sobre como essas novas mercadorias cosméticas permitem a inclusão ao representarem e contemplarem o cabelo crespo no consumo do novo século. Continua-se a reflexão, então, ao perceber-se como tais bens de consumo podem vir a reforçar as práticas sociais desse grupo e como essa busca pela estética negra reflete em um mercado que, agora, busca incluir e evidenciar a beleza negra.

Como é comum no sistema capitalista, o mercado se apropria de marcas identitárias e produtos culturais transformando-os em novos produtos para a moda e a indústria cultural. Esse fenômeno também se dá com os estilos de cabelos negros, e é incorporado no visual da população negra e branca. Para Nilma Lino Gomes (2006), a popularização de expressões culturais que antes eram vistas como negras pode apresentar também ganhos para a população negra, podendo fomentar a adoção de novas estratégias de resistência e, ainda, impulsionar a organização política negra em torno de questões atuais. Assim, as mudanças sociais, culturais e econômicas podem vir a alterar identidades e comportamentos dando-lhes novos significados.

Para Sansone (2000), apesar do discurso a respeito da cultura negra enfatizar a ancestralidade e a oposição ao comércio, a relação com a modernidade e a mercantilização do Novo Mundo se dão de modo 
tão antigo quanto a criação da cultura afro-brasileira. Quanto ao discurso acerca da naturalidade do cabelo, de modo algum este discurso se contrapõe ao uso de produtos e novas técnicas capilares. O cabelo considerado natural é aquele que parece não ser manipulado, sendo assim mais ligado à aparência e ao não uso de produtos químicos que mudam drasticamente a textura do cabelo.

Ainda, a incorporação das intervenções estéticas no cabelo crespo pelo mercado demonstra que estas operam em um terreno mapeado pelos códigos simbólicos de outras culturas. Desse modo, Gomes (2006) afirma que a existência de um maior número de produtos étnicos acaba construindo novas possibilidades para o cabelo negro. O mundo da estética e da cosmetologia sempre investiu em produtos para mulheres brancas, os quais eram generalizados para as de outros segmentos étnicos/raciais. Desde os cremes faciais, batons, bases, sombras, shampoos, cremes redutores dos cachos dos cabelos até as cores das meias finas de nylon, a indústria de cosméticos durante anos privilegiou o padrão branco e investiu nesse tipo de consumidor, generalizando o fato de que, se era bom para os brancos, também o seria para os outros grupos raciais. Assim, a introdução de produtos étnicos no Brasil, via mercado norte-americano, pode ser vista não somente na perspectiva da exclusão gerada pela globalização. Contraditoriamente, no contexto capitalista, o racismo foi um dos motivos do surgimento do mercado de produtos étnicos como uma das muitas estratégias antiracistas. (GOMES, 2006, p. 204).

No Brasil, vive-se a contradição da oferta majoritária de produtos para a pele branca em uma sociedade miscigenada. Desse modo, o desenvolvimento do mercado cosmético para a pele negra e também para os cabelos crespos pode ser visto como um direito conquistado principalmente pelas mulheres negras. 
Se antes os empresários do meio cosmético ignoravam o consumo da população negra porque acreditavam que esta não tinha capacidade de consumo, com o crescimento da população negra de classe média no século XXI, a indústria cosmética viu-se obrigada a repensar suas mercadorias, assim como a representação da mulher negra nas mídias. A pouca visibilidade dada à mulher negra na questão estética começa a ser questionada, o que pode ter influenciado a abertura de novos mercados que inseriram o homem negro, mas principalmente a mulher negra, como público consumidor. De certa forma, é necessária a identificação da população negra com as novas mercadorias ofertadas, principalmente através de imagens e discursos que possibilitem a valorização da beleza negra. Todavia, o aumento da representação da mulher negra na mídia também pode ser relacionado à “moda” de ser negro e à disseminação e apropriação da cultura negra pelos brancos.

\section{Aspectos metodológicos}

Para dar conta do objeto deste estudo, que são as interações entre as novas mercadorias de consumo para o cabelo crespo e a construção de uma estética negra pela mulher negra, propõe-se uma etnografia de modo a compreender aspectos que circundam essas possíveis relações.

Na antropologia contemporânea, surgiram novas maneiras de etnografar e compreender uma cultura através dos novos meios comunicacionais e da centralidade da imagem no século XXI. Essa nova possibilidade etnográfica, voltada às imagens, acaba por modificar os modos de escrita etnográfica e, também, a relação entre etnógrafo e etnografado. Logo, nascem novas percepções sobre a subjetividade com implicações políticas, éticas e estéticas. 
Ainda é importante destacar que as mídias digitais não criam experiências paralelas, sendo que o online e o offline se apresentam como um contínuo. Para Miskolci (2013), as mídias digitais medeiam a vida offline, mas de modo algum criam um universo social à parte.

Diante da grande frequência de produção de imagens, que estão por todo lugar, é certamente na Internet que a grande maioria está agrupada, podendo ser encontradas através de portais de busca, mas, mais que isso, em sites que visam somente o compartilhamento de vídeos. Quando se pensa em compartilhamento de vídeos, o primeiro site que nos vem à mente certamente é o Youtube, sendo que este foi o primeiro a proporcionar a visualização e compartilhamento de vídeos e, ainda hoje, se mostra o mais popular do segmento. No Youtube, qualquer pessoa pode acessar, visualizar e postar vídeos e, a cada vez que acessa um vídeo, é defrontado com inúmeros links de outros vídeos que se relacionam de algum modo com o visualizado. Assim, pode-se dizer que o Youtube é uma comunidade virtual em torno do compartilhamento de imagens, proporcionando novos modelos de criação surgidos através das novas tecnologias digitais.

A partir do apresentado, propõe-se um olhar etnográfico em relação a essa forma de produção imagética e como esta pode representar uma nova maneira de explorar e apresentar uma identidade e sua relação com o consumo. Como as youtubers selecionadas apresentam em seus vídeos sua construção estética e associam sua identidade como mulheres negras aos novos produtos para cabelos crespos, acredita-se que o meio digital apresenta consideráveis especificidades que podem contribuir para o entendimento sobre o tema.

No Youtube, foram selecionadas algumas dentre as diversas youtubers que tratam da questão estética do corpo negro e cabelo crespo. Após a visualização dos vídeos e coleta dos dados, unificou-se as per- 
cepções através de temas que se percebeu se mostrarem comuns para todas as youtubers. Nestes temas, busquei refletir sobre a afirmação estética, as relações com empresas de produtos cosméticos e mercadorias, as falas sobre afetividades em torno dos cabelos e também o discurso em torno da representatividade da mulher negra e a visibilidade e construção da beleza negra.

\section{Mercadorias estéticas para cabelos alisados e crespos e a mulher negra}

A youtuber Priscila, quando fez sua transição capilar, já morava na Espanha e, devido à dificuldade de acesso a produtos para cabelos crespos, lembra que utilizava os cosméticos para cabelos secos, eram estes os que melhor se adequavam a sua textura e fio. A youtuber traz um depoimento muito relevante ao pensarmos sobre a grande disparidade entre produtos para alisamento e produtos para cabelos crespos. Ela denota como principal diferença a diversidade entre produtos e procedimentos que existem há muitos anos para alisamento capilar, em contraponto aos produtos para cabelos crespos que são uma inserção do mercado vinda do final do século XX e início do XXI.

Mas eu acho totalmente errado comparar o nosso cabelo com a moda. Porque se a gente for parar pra analisar... vamos lá analisar! Primeira coisa: a gente saiu daquele pente quente que a gente esquentava na boca do fogão pra migrar pra chapinha. A chapinha foi uma explosão, uma novidade que todo mundo queria ter. A primeira chapinha que eu tive a minha mãe comprou na loja do Gugu, pra vocês verem como a coisa é antiga. A gente comprou ela na loja do Gugu, ela custou mais ou menos uns 42 reais, que naquela época eram muitos dinheiros. E ela era uma chapinha super básica, ou seja, ela não tinha nada, ela não tinha termostato, ela não tinha nem luzinha direito ela tinha, gente. Era uma placa assim tipo de ferro 
de passar roupa mesmo, normal, cinza, e nem esquentava tanto assim. Com o passar do tempo, a chapinha foi evoluindo, apareceram chapinhas de íons vermelhos, íons azuis, nem sei se eu tô falando certo, placa de cerâmica, placa de diamante, chapinha que faz milagre, chapinha que... gente, apareceu chapinha de tudo quanto é tipo. A melhor chapinha, acho que ela já existe, ela tá no mercado e vão inventar uma melhor ainda. Assim como os relaxamentos, alisamentos e progressivas. Eles também evoluíram muito, porque eu me lembro que o primeiro relaxamento que eu utilizei foi aquele do Netinho da caixa assim, duas meninas, acho que era toft, soft, ploft, não lembro. E, depois desse alisamento, eu comecei a usar coisas mais fortes como highlife, salon line. Mano, pode falar um relaxamento aí, pode falar, fala... Tenho certeza que eu já usei. E quando saiu a moda da progressiva? Primeiro, era uma progressiva normalzinha. Progressiva pra alisar o cabelo. Depois foi saindo as 300 milhões 359 mil escovas. Escova de chocolate, escova definitiva, de chocolate branco, escova de açúcar, escova de cristal, de diamante, marroquina, japonesa, chinesa, tailandesa. Mano, saiu muita escova. Conforme o povo vai gostando da coisa, a coisa vai evoluindo. E se você for parar pra olhar à sua volta, a sociedade tá na moda porque todo mundo tem o cabelo alisado, todo mundo já fez uma progressiva, todo mundo já fez uma escova de chocolate, todo mundo já tem uma chapinha com águas do Rio Nilo com diamantes céu. Todo mundo tem. E agora, porque você resolveu voltar ao seu cabelo natural, que é uma coisa sua, que já nasceu com você, você tá na moda? (Priscila).

Com o depoimento de Priscila, percebe-se uma crítica à relação do cabelo crespo com a moda, de maneira a enfatizar que os usos do cabelo crespo não são algo passageiro. Ela retoma a ideia de naturalidade do cabelo e demonstra, através de uma linha do tempo que expressa sua experiência, as inovações para alisamento dos cabelos crespos. Fica aqui, também, mais uma vez evidente a imposição de um padrão de beleza que se propaga através dos meios de comunicação, já que o primeiro alisamento que Priscila faz é da loja do apresentador Gugu. 
Assim como Priscila recorda da propagação do ideal de beleza ligado ao cabelo liso, Débora também lembra como foi mais difícil sua transição capilar devido à dificuldade em encontrar cremes específicos para hidratar seus cabelos. Hoje, ela vê um maior número de produtos no mercado e com eles maiores possibilidades quanto à versatilidade dos cabelos crespos. Vale ressaltar aqui que, segundo Sheth et al. (2001), produtos que geram valor social também podem vir a gerar valor emocional, aumentando o sentimento de autoaceitação, pertença, autoconfiança e outros. Autoestima, estima social e sentimento de pertença estão diretamente relacionados às decisões de consumo, assim como as afetividades que circundam esse processo. Assim, pode-se relacionar a autoestima da mulher negra com novas mercadorias que possibilitam uma inserção no consumo, mas também social.

Em comentário, Eva Lima admite sua preferência pelas linhas para crespos, mas não descarta o uso dos produtos generalistas:

Ah! Sim eu prefiro produtos específicos para cabelo crespo também, porque são mais nutritivos, porém eu uso vários para testar e passar o feedback para as meninas. (Eva Lima).

Mesmo assim, Eva não disfarça o entusiasmo ao encontrar uma linha para cabelos cacheados em meados de 2013:

Várias vlogueiras já gravaram vlog aqui no Youtube, resenhas, reviews, falando sobre essa linha da Seda e todas com a opinião unânime de que foi muito legal assim, pelo menos essa intenção de criar uma linha pra cabelos crespos específica, o que é difícil no nosso mercado. Então a gente ficou muito contente. Acho que todas as vlogueiras de cabelo cacheado e crespo resolveram testar e mostrar pra vocês o que achou. (Eva Lima).

No ano seguinte, Eva testa produtos de uma nova empresa que 
foca em uma linha para cabelos crespos e cacheados e afirma, ao falar das novas mercadorias: "Um boom, uma revolução no mercado mesmo". Mesmo com novos produtos para cabelos crespos, Eva continua utilizando e afirmando que é possível fazer uso de um produto para cabelos lisos nos cachos, porém não é obtido o mesmo efeito.

A gente não vai comprar um produto pra cabelo liso e usar no nosso cabelo. Pode dar certo? Pode. Vai finalizar também? Vai. Mas não é a mesma coisa. A gente sabe que o nosso cabelo sente necessidade de óleos, sente necessidade de manteiga, sente necessidade de uma hidratação, de uma nutrição mais potente. Quando uma empresa se preocupa em criar produtos específicos pro nosso tipo de cabelo, isso é muito bom. A gente vai ter um resultado muito melhor, a gente vai ficar muito satisfeita e a gente, claro, a gente vai comprar muito mais daquela empresa que se preocupou com isso do que com aquela que não se preocupou tanto. (Eva Lima).

Além de evidenciar a preferência pelas linhas para cabelos crespos, Eva atenta, neste comentário, para a fidelização do cliente à marca. Ao sentir-se contemplada e percebida pela marca em suas necessidades, as mulheres negras, assim como a maioria dos consumidores, tendem a voltar a adquirir produtos desta mesma marca.

Se o investimento em um cabelo alisado é marcado por tempo e dinheiro despendido, para o cabelo crespo não é diferente. "É sempre bom você investir nessas coisinhas pra cabelo cacheado”, diz Ana Lídia. Ela lembra como seu cabelo precisou de mais cuidados depois do big chop, já que agora, além de crespo, o seu cabelo estava seco e precisava de tratamentos especiais. Muitas das seguidoras não sabem como cuidar dos seus cabelos e, para começar, a dica que Ana dá é a de procurar cremes adequados ao seu tipo de cabelo, focando então nos produtos para crespos e cacheados. Além disso, muito presente nas dicas de diversas youtubers são as receitas caseiras, que improvisam produtos alimentícios da cozinha misturados com cremes e máscaras 
hidratantes.

Vale salientar que algumas youtubers têm cabelo tipo 3 (cacheadocrespo) e outras tipo 4 (crespo mais intenso) e que esta diferença de textura também compreende necessidades e cuidados específicos. Assim, para além de linhas para cabelos crespos, algumas empresas já perceberam as diferenças entre os fios com cachos e investem em produtos especiais para cada tipo de cabelo (tipos 3 e 4). Esta percepção também é vista de maneira muito positiva pelas youtubers e seguidoras.

Débora recorda que a única coisa que sabia sobre cabelo cacheado durante a transição é que Gota Dourada (marca de produtos) era bom para o cabelo. Em vídeo após um ano do início de sua transição, Débora aprendeu a cuidar dos seus cabelos e tem uma rotina diária de tratamento. Seu procedimento consiste em cuidados cotidianos que são: lavagem e hidratação, no intervalo de um dia; além de usar cremes para cabelos crespos, mas sem utilizar todos os dias o redutor de volume, para o seu cabelo "não acostumar".

Além dos produtos para cabelos crespos, percebem-se nesta etnografia diversas outras mercadorias para cabelos que reforçam a beleza das mulheres negras. Podem-se citar aqui turbantes, pentes garfo, acessórios e outros. Enquanto algumas mulheres, como Eva, usam acessórios tipicamente ligados à cultura negra como os turbantes, outras, como Ana, utilizam acessórios comuns como tiaras, presilhas e outros. Independente do tipo de acessório, acredita-se que todo produto que propicia uma autoestima mais elevada e também uma percepção de si própria como bela, pode ser encarado como uma mercadoria que reforça a estética negra. Pode-se, ainda, afirmar aqui (CERTEAU, 1994) que as práticas de consumo, seja dos produtos para cabelos crespos, seja dos acessórios, podem ser vistas como uma possibilidade de 
agência que permite a ressignificação dessas mercadorias por parte das mulheres negras. Muito mais que meros produtos de consumo, pode-se pensar estas mercadorias como possibilidades de a mulher negra reconstruir um lugar de beleza que vá além do padrão de beleza hegemônico.

Turbantes e lenços também são a dica de Maraisa para quem está em período de transição e quer disfarçar a diferença entre as texturas. Para Maraisa, usar o turbante é um jeito de ficar bonita quando o cabelo não está em um bom dia, e ainda atenta: "Todo mundo fala que cabelo moldura [...], por isso que muitas mulheres quando cortam, quando perdem o cabelo, isso mexe muito”.

Débora afirma que adora os acessórios para cabelos, principalmente os grampos por sua versatilidade. Ela também faz muitos penteados com turbantes e lembra que estes valorizam seus traços negros. Sobre turbantes, Débora afirma: "Quem me conhece sabe que eu adoro turbante, que é uma coisa que me representa muito."

Além de adorar turbantes, Débora reforça a ideia de que turbantes são parte da cultura negra, sendo um símbolo de poder dentro desta, apesar de terem sido proibidos durante a escravidão no Brasil. Dessa maneira, a youtuber afirma ser contra o uso de turbantes por pessoas brancas, principalmente por aquelas que fazem uso devido à moda $\mathrm{e}$ não conhecem o seu significado cultural. Além dos turbantes, outros adereços e penteados crespos, como as tranças nagôs, são vistos por ela como apropriação cultural quando usados pela população branca.

Ademais, o cuidado ao criar os produtos, nomeá-los e até mesmo rotulá-los não passou despercebido por estas mulheres. Dani afirma adorar os produtos feitos especificamente para cabelos como os seus, crespos. Para além do produto que se adéqua melhor às necessidades dos seus cabelos, Dani também adora os rótulos e mensagens que mui- 
tas empresas escrevem dando apoio às mulheres negras e valorizando sua beleza e seu cabelo. Porém, viu-se tanto comentários positivos em relação a linhas que fortaleciam a beleza negra em seu posicionamento, como outras linhas que, pode-se dizer, “escorregaram” na hora de criar o conceito do seu produto. Ilustrando essas afirmações, temos um comentário de Eva em seu canal, onde a youtuber atenta para o cuidado que deve ser tomado ao nomear uma nova linha de produtos para cabelos crespos ou inserir informações tratando de corpos negros e sua cultura.

Eu recebi uns produtinhos da Soft Hair uma linha chamada "Mulata”, inclusive isso gerou um pouco de desconforto no grupo porque a gente não concorda, pela menos eu não concordo muito, com esse termo que é utilizado, tá? Eu sei que tem gente que não liga muito, mas assim, existe todo um contexto, toda uma história por trás desse nome. Então assim, eu nunca fui muito, né? Depois de saber do outro significado que tem, eu nunca gostei muito. Então, uma sugestão que a gente deixa pra marca é a mudança do nome. [...] Eu tenho certeza que muita gente vai deixar de comprar por causa do nome. (Eva Lima).

Diferente desta linha apresentada por Eva, encontram-se também linhas que fazem uso de termos da cultura negra que se tornam fortalecedores de uma estética da mulher negra. Um exemplo é o produto chamado "Bora Definir? Black é power”, que evidencia a força do movimento Black Power, estendendo-se até os dias de hoje na influência dos cabelos crespos e da resistência estética e política negra.

Outra ideia interessante, vinda de algumas marcas, é a de pesquisar processos caseiros que as mulheres negras aplicam nos cabelos e, então, torná-los produtos pensados propriamente para os cabelos. Assim, por exemplo, percebeu-se que muitas mulheres negras utilizavam maionese (o produto alimentício) para hidratar os cabelos. Vendo esta oportunidade, uma empresa do ramo cosmético criou a "maionese ca- 
pilar”, inspirada na receita caseira e da qual até mesmo a embalagem remete ao produto alimentício.

Apesar da crescente popularização de produtos para cabelos crespos, ainda temos regiões do país em que sua aquisição se torna difícil. Seja pela localidade, seja pelo preço, nem todas as mulheres negras brasileiras (mesmo as de classe média) têm acesso a produtos específicos para cuidados com seus cabelos naturais.

Assim, mesmo que a mulher queira deixar o cabelo natural, a falta de conhecimento sobre cuidados, a dificuldade de informação e a carência de produtos pode levá-la a tomar a decisão do alisamento. Para Nátaly, o maior obstáculo das mulheres negras em relação aos seus cabelos é aprender a cuidá-lo e amá-lo, assim, ela afirma: “a dificuldade maior não é porque a pessoa não tem dinheiro, não tem poder aquisitivo alto, é a pessoa não saber usar o produto.” De modo que poucas mulheres negras têm o privilégio de aprender a cuidar dos seus cabelos naturais em casa, demonstra-se assim a importância das youtubers como uma espécie de propagadoras de conhecimento, ensinando cuidados, técnicas, manuseios, penteados e todo tipo de tratamento para cabelos crespos. Para além da representatividade negra, cria-se uma rede de ensinamentos e aprendizagem onde circulam informações sobre a beleza negra.

Começa até pela maquiagem. Você que é mulher negra, você vê o quanto é difícil você encontrar uma base do seu tom, um tom que você não fique cinza. Então, assim, pra mim, usar maquiagem é uma militância, porque eu tô falando aqui "Gente, eu tô aqui, eu consumo, eu uso creme de cabelo, eu me visto, eu quero tá bonita.” (Débora).

Com este comentário, Débora traz novamente à tona a ideia de que a beleza negra não é apenas uma questão estética, mas transcende em direção a uma posição política, demonstrando também que adquirir 
mercadorias é também apropriar-se delas para torná-las signo (DOUGLAS; ISHERWOOD, 2006; CERTEAU, 1994).

Logo, pode-se ver não só o mercado criando um novo discurso sobre beleza, mas também um discurso sendo criado pelas mulheres negras ao apropriarem-se dos produtos de beleza negra. Com a autoestima elevada, obtendo autoaceitação e amando seus cabelos, as mulheres negras estão politizando a sua estética como meio de se opor ao racismo. As novas mercadorias para cabelos crespos possibilitam não apenas novos e melhores cuidados dos fios, mas também a visibilidade da mulher negra no consumo e nas mídias digitais, fortalecendo identidades, gostos e preferências. Além disso, as empresas que criam produtos para cabelos crespos tendem a fazer parcerias com as youtubers, de modo que também fortalecem uma nova rede de ensinamentos e aprendizagens em torno dos cabelos crespos.

\section{Considerações Finais}

Neste estudo, buscou-se compreender as novas possibilidades de consumo estético direcionado ao cabelo crespo em sua interação com a busca da mulher negra pelo reconhecimento de uma beleza negra, que se relaciona não apenas à dimensão estética, mas também política e social. Dessa maneira, procurou-se compreender o consumo em suas interações sociais, de modo a entender os ressignificados dados pelos indivíduos que consomem.

Para finalizar, é preciso lembrar que o consumo de mercadorias para cabelos crespos, seja de produtos capilares, seja de acessórios e apliques, deve ser visto como uma ressignificação do consumo por parte das mulheres negras. Para autores como Certeau (1994), a ressignificação do consumo pode ser vista como uma maneira de sair do 
lugar de dominação imposto a uma população, neste caso as mulheres negras. Assim, as mulheres negras geram, em torno de seus cabelos, táticas de consumo que politizam estas mercadorias, e que se tensionam com as estratégias vindas das empresas de cosméticos. Ainda, essas táticas de consumo estético que são criadas pelas mulheres negras são também modos de politizar a beleza negra e de transformar a estética em uma ferramenta de luta contra o racismo. A mulher negra ao politizar esses produtos também politiza seu corpo dando visibilidade a sua negritude (FANON, 2008). Os bens de consumo, então, carregam significados que lhes são dados pelas consumidoras negras, mas não se distanciam totalmente do propósito pelo qual as empresas de cosméticos os comercializam.

Para além de uma visão de consumo massificada, a espécie de agência permitida pelo consumo, nesta perspectiva, permite que as mulheres negras deem significados próprios a mercadorias produzidas pelas empresas de cosméticos. Desse modo, vê-se as "maneiras de fazer” (CERTEAU, 1994) nos meios que as mulheres negras encontram para ressignificar o uso dos produtos de beleza, na politização dos produtos e acessórios capilares, na transformação dos bens de consumo em parte da sua luta pela visibilidade do corpo negro.

Além disso, as “artes de fazer” podem ser compreendidas nos usos cotidianos dados a estas mercadorias como modo de criar uma resistência política e social ao racismo. As “artes de fazer” estão no ato da mulher negra assumir o seu cabelo crespo, nos cuidados e manuseios deste cabelo, nas escolhas de consumo, na autoaceitação e elevação da autoestima das mulheres negras, nas astúcias diárias e práticas de resistência capazes de ressignificar os produtos capilares. Assim, percebeu-se que as novas mercadorias de consumo para cabelos crespos se relacionam com aspectos da cidadania e da inclusão da mulher 
negra em uma sociedade que vem aprendendo a contemplar também a beleza negra.

Outro ponto importante é o de que a mudança na esfera do consumo se mostra relacionada principalmente à demanda e luta do movimento negro. Para além do que é vislumbrado neste artigo, acreditase que políticas públicas que propõem uma tentativa de compensação para a população negra, como o caso das cotas raciais nas universidades, também permitem que a mulher negra se insira no mercado de trabalho, podendo reforçar suas demandas através de uma visibilidade maior como cidadã. O consumo tem a capacidade de mudar estereótipos e criar imagens positivas, mas é preciso ressaltar que não é capaz de sanar todas as bases de exclusões sociais e políticas.

Para além da estética, pode-se afirmar que a luta pela visibilidade e inclusão da mulher negra através de uma beleza negra é também uma pauta política que busca dar visibilidade ao corpo negro. Apesar do contexto capitalista, e das empresas de cosméticos visarem o lucro, ao atender esta demanda das mulheres negras em relação aos produtos para cabelos crespos, as empresas também acabam por valorizar a cultura negra. Tanto no campo das pesquisas, quanto no consumo, é preciso afirmar a visibilidade do corpo negro, assim como perceber que este vai além da dimensão estética, também explorando debates sociais e políticos.

\section{Referências}

CANCLINI, Néstor García. Consumidores e cidadãos: conflitos multiculturais da globalização. In: Consumidores e cidadãos: conflitos multiculturais da globalização. Editora UFRJ, 1996.

CERTEAU, Michel de. A invenção do cotidiano. Petrópolis: Vozes, 1994.

COUTINHO, Cassi Ladi Reis. A estética negra em Salvador (1996-2005). 
XXV Simpósio Nacional de História, Fortaleza, 2009.

CRUZ, Cíntia Tâmara Pinto da. Os cabelos mágicos: identidade e consumo de mulheres afrodescendentes no Instituto Beleza Natural. 2013.

DOUGLAS, Mary; ISHERWOOD, Baron. O mundo dos bens: para uma antropologia do consumo. Rio de Janeiro: UFRJ, 2006.

FANON, Frantz. Pele negra, máscaras brancas. Salvador: SciELOEDUFBA, 2008.

FIGUEIREDO, Ângela. Beleza pura: símbolos e economia ao redor do cabelo do negro. Monografia para a conclusão do curso de Ciências Sociais. 53 folhas. Faculdade de Filosofia e Ciências Humanas. Universidade Federal da Bahia, Salvador, 1994.

GOMES, Nilma Lino. Sem perder a raiz: corpo e cabelo como símbolos da identidade negra. Belo Horizonte: Autêntica, 2006.

GONÇALVES, Maria Alice Rezenda; RIBEIRO, Ana Paula Alves. Mais que feijoada e samba: notas sobre a cultura negra brasileira. In: LEITÃO, Débora Krischke; DE OLIVEIRA LIMA, Diana Nogueira; MACHADO, Rosana Pinheiro. Antropologia e consumo: diálogos entre Brasil e Argentina. Porto Alegre: Ed. AGE, 2006.

HONNETH, Axel. Luta por reconhecimento: a gramática moral dos conflitos sociais. São Paulo: Ed. 34, 2033.

MISKOLCI, Richard. Novas conexões: notas teórico-metodológicas para pesquisas sobre o uso de mídias digitais. Revista Cronos, v. 12, n. 2, 2013.

SANSONE, Livio. Os objetos da identidade negra: consumo, mercantilização, globalização e a criação de culturas negras no Brasil. Mana, v. 6, n. 1, p. 87-119, 2000.

SHETH, Jagdish N.; MITTAL, Banwari; NEWMAN, Bruce I. Comportamento do cliente: indo além do comportamento do consumidor*. São Paulo: Atlas, 2001.

XAVIER, Giovana. Domando os fios e civilizando os corpos: a construção da beleza afro-americana em alguns jornais e revistas negros de Chicago no pós-abolição (1918-1922). XXVI Seminário Nacional de História, São Paulo. 2011. 


\section{Resumo:}

Neste artigo, visa-se tratar das interações entre novas mercadorias de consumo e a beleza negra, mais especificamente o cabelo crespo. Dessa maneira, procura-se observar e analisar a possível construção da identidade estética das mulheres negras. Através de uma etnografia digital em canais do Youtube que tratam sobre cabelos crespos, busca-se compreender a relação entre o consumo de produtos para o cabelo crespo e a construção de uma beleza negra pelas mulheres negras. $\mathrm{O}$ intuito de fazer uma etnografia digital, que se relaciona também à militância fora das redes sociais, é compreender os usos dos produtos, além das relações entre as mulheres negras, as mídias e as novas mercadorias estéticas a fim de perceber possíveis espaços de visibilidade para a beleza negra através do consumo. Assim, através das youtubers, afirma-se uma luta para visibilidade e inclusão da mulher negra através da beleza como pauta política e atual que vai além do consumo e além da esfera digital.

Palavras-chave: Cabelo Crespo; Beleza Negra; Mulher Negra; Consumo Antropológico; Mídias Digitais. 


\begin{abstract}
:
This article aims to deal with the interactions between new consumer products and black beauty, more specifically curly hair. In this way, we seek to observe and analyze the possible construction of the aesthetic identity of black women. Through a digital ethnography on Youtube channels that deal with curly hair, we seek to understand the relationship between the consumption of products for curly hair and the construction of a black beauty by black women. The purpose of making a digital ethnography, which is also related to militancy outside social networks, is to understand the uses of products, as well as the relations between black women, the media, and new aesthetic products, in order to perceive possible spaces of visibility for black beauty through consumption. Through the youtubers, a struggle for visibility and inclusion of black women is affirmed through beauty as a political and current agenda that goes beyond consumption and beyond the digital sphere.
\end{abstract}

Keywords: Curly Hair; Black Beauty; Black Woman; Anthropological consumption; Digital Media.

Recebido para publicação em 25/09/2019. Aceito em 04/10/2019. 